\title{
The Effects of Discrimination Experience on Life Satisfaction of North Korean Refugees: Mediating Effect of Stress
}

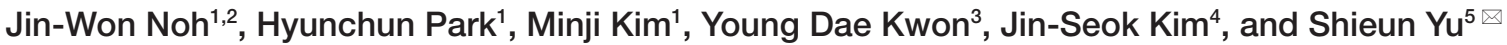 \\ ${ }^{1}$ Department of Healthcare Management, Eulji University, Seongnam, Republic of Korea \\ ${ }^{2}$ Global Health Unit, Department of Health Sciences, University Medical Centre Groningen, University of Groningen, Groningen, the Netherlands \\ ${ }^{3}$ Department of Humanities and Social Medicine, College of Medicine and Catholic Institute for Healthcare Management, \\ the Catholic University of Korea, Seoul, Republic of Korea \\ ${ }^{4}$ Department of Social Welfare, Seoul Women's University, Seoul, Republic of Korea \\ ${ }^{5}$ Clinical Trial Center, Korea University Medical Center, Seoul, Republic of Korea
}

Objective This study investigated the mediation effect of stress between the experience of discrimination and life satisfaction among North Korean refugees who resettled in South Korea. The findings of the current study provide empirical evidence for the need of social interventions to mitigate adverse effects of stress on North Korean refugees who are subject to social discrimination on a daily basis.

Methods In this study, we included 500 subjects among 2,138 North Korean refugees who took refuge in South Korea in 2007. The interview started from April 6th 2009 and finished on May 25th 2009. We conducted moderator effect analysis with Path analysis was conducted because we confirm the experience of discrimination was affected by life satisfaction and stress can affected life satisfaction as a moderator.

Results The experience of discrimination significantly affects stress and stress significantly affects life satisfaction. However, the experience of discrimination was not directly related to life satisfaction. The more stress the study respondents experienced, the lower the life satisfaction they reported.

Conclusion The present finding suggests that the effects of discriminating experiences on the life satisfaction of North Korean refugees in South Korea were mediated by their own perceived stress.

Psychiatry Investig 2018;15(1):49-53

Key Words Discrimination, Life satisfaction.

\section{INTRODUCTION}

North Koreans have a serious economic crisis, as millions of citizens are suffering in famine caused by natural disasters, international isolation and death of Il-Sung Kim in the 1990s. Since then society has collapsed and has seriously closed the organizational structure. ${ }^{1,2}$ Due to this breakdown, a new birth of North Korean refugees has been made and also many of them have had the opportunity to be introduced to South Korea via China and other third countries. ${ }^{2}$ North Korean refugees en-

Received: May 2, 2016 Revised: November 5, 2016

Accepted: April 18, 2017 Available online: November 16, 2017

$\triangle$ Correspondence: Shieun Yu, PhD

Clinical Trial Center, Korea University Medical Center, 73 Inchon-ro, Seongbuk-gu, Seoul 02841, Republic of Korea

Tel: +82-2-2286-1418, Fax: +82-2-2286-1419, E-mail: seyou1224@hanmail.net

(c) This is an Open Access article distributed under the terms of the Creative Commons Attribution Non-Commercial License (http://creativecommons.org/licenses/by$\mathrm{nc} / 4.0$ ) which permits unrestricted non-commercial use, distribution, and reproduction in any medium, provided the original work is properly cited. tering South Korea now has reached 28,133 people in June 2015 , which is a sharp contrast to 1998 , only about 947 people entered. $^{3}$

North Korean refugees in the South Korean society happen to relocate to a third country and political asylum was approved by the third country for reasons such as discrimination. ${ }^{4}$ According to the study by Han et al. ${ }^{5}$ and Park, ${ }^{6}$ the general perception of South Koreans towards North Korea was not favorable. South Koreans had lower favorability and confidence about the refugees than the disabled or local people in Korea and migrant workers. Especially the wealthy metropolitan residents and highly educated people have more negative perceptions about the refugees. ${ }^{7}$ This discrimination will have a negative impact on the adaptation of the refugees. In a study conducted by Kim and Lee, ${ }^{8}$ discrimination of refugees influenced the psychological burden.

The problem with the discrimination experiences of refugees can be a barrier for the social integration between South and 
North Korea and whether or not a harmonious multicultural society can flourish. Discrimination is a major cause of stress and depression among the settlers and one of the most important factors affecting the mental health. ${ }^{9,10}$ These mental health problems such as anxiety and depression can affect the quality of life. ${ }^{11}$ Deterioration of the quality of life may be associated with life satisfaction. George has said that life satisfaction was cognitive appraisal of personal influenced by social factors and guidelines for psychosocial well-being. ${ }^{12}$

Bardasi Francesconi examined the satisfaction of life and discrimination among non-regular workers in Britain. ${ }^{13}$ As a result, the discrimination experience affects both job satisfaction and life satisfaction negatively. In a study by Nam et al., ${ }^{14}$ they mentioned that discrimination among spinal disabilities does not have a direct impact on life satisfaction. As such, the results look different from previous studies on discrimination and life satisfaction, suggesting that discrimination may not have a direct impact on life satisfaction. In other words, it is possible that the discrimination experience acts as an indirect effect between life satisfaction and other related factors.

There is a lack of researches on exactly how much discrimination affects satisfaction in their lives. In addition, most studies on North Korean refugees were confined to mental health and traumatic experience. ${ }^{2,15}$ When we consider stress due to the refugees everyday life, studies to alleviate their quality of life are very necessary. The purpose of this study is to identify the mediating effect on stress between discrimination and the satisfaction of life for the refugees. Through this, we will provide a positive and active accept-inducement for the recognition and discrimination against refugees. Also we will utilize practical interventions for improving the quality of life through the development of programs. Furthermore, this study will be utilized as a basis to establish the policy alternatives so that the community can improve their quality of life by accepting the refugees without any discrimination and all members of South Korean society.

\section{METHODS}

\section{Subjects and data}

In this study, we included 500 subjects among 2,138 North Korean refugees who took refuge in South Korea in 2007 (January 1st to December 31th). Among the North Korean refugees who came 1,447 were not contacted, 107 did not agree to participate in this study. Among the 584 who agreed to participate, some of subjects who could not be contacted and did not allow participation were excluded. Finally, 500 subjects were conducted with one-person interview. The interview started from April 6th 2009 and finished May 25th 2009. The study protocol and required consent forms were verified and approved by the Institutional Review Board of the Severance Hospital (09-0005) before the interviews took place.

\section{Variables}

Demographic variables included gender, age, level of education in North Korea and South Korea, marital status, religion and employment status. In this study, we used the discrimination scale developed by Williams et al. ${ }^{16}$ to see general discrimination experience among North Korean refugees. This scale is composed of nine questions such as 'I am treated as inferior' and 'I am not treated as a smart man'. These questions show how many North Korean refugees had these experiences from South Korean everyday life using 4 -Likert scales. The minimum score is nine and the maximum score is 36 . The higher the score meant the more discrimination North Korean refugees experienced. The Cronbach's alpha value was 0.750 for the study of Williams et al. ${ }^{16}$ and 0.88 for this research.

In the study, education in North Korea is divided from uneducated; dropped out or graduated, drop out of high school graduation, college graduation, or dropout. Demographic and socio-economic variables included gender, age, level of education, marital status, religion, and employment status. With 11 questions, we measured stress of North Korean refugees. The measure was developed by literature review of stress scale and we selected questions from the questions of published studies. ${ }^{17}$ The range of score is ' 0 ' (never), ' 1 ' (a little), ' 2 ' (much), and ' 4 ' (always). The minimum score is 11 and the maximum score is 44 . The Cronbach's alpha of this measure was 0.77 .

For measuring life satisfaction, the satisfaction with life scale (SWLS) developed by Diener et al..$^{18}$ was used. The satisfaction with life scale can measure how much people are satisfied about general life. This measure was composed of 5 questions that show one common factor. The minimum score is seven and the maximum score is 35 using 7-Likert scale. From the range of scores between five to nine people meant that they were not very satisfied with life. From 10 to 14, people were not satisfied with life. From 15 to 19, people were generally a bit satisfied with life from 21 to 25 , people were satisfied with life. From 26 to 35, people were very satisfied with life. The Cronbach's alpha of this measure was 0.80 .

\section{Statistical analysis}

We conducted analysis of frequency for general characteristics and correlation analysis for correlation among experience of discrimination, stress, life satisfaction using Pearson's correlation coefficient. The moderator effect analysis with Path analysis was conducted because we confirmed that the experience of discrimination was affected by life satisfaction, and stress can affected life satisfaction as a moderator. In this study, absolute fit index and incremental fit index were used 
for goodness of fit in the model of path analysis.

The absolute fit index is the general indicator for evaluating the goodness of fit of the model. However, since chi square test is very sensitive to the degree of freedom and $\mathrm{N}$-value, another indicator is needed. In this study, we used root mean square error of approximation (RMSEA) for goodness of fit, which can evaluate the model from population not sample. With lower 0.08 , the model is appropriate. ${ }^{19}$

The incremental fit index was used to compare goodness of fit of models we made. This study used comparative fit index (CFI). CFI compares researcher's model with a baseline model supposing latent variables are independent in the baseline model. CFI is higher 0.95 , thus the goodness of fit of model was good. ${ }^{20}$

In this study, RMSEA was 0.000 and CFI was 1.000, which is appropriate for goodness of fit. Stata, version 13.1 (StataCorp LP, College Station, TX, USA) software was used.

Table 1. General characteristic of subjects

\begin{tabular}{|c|c|c|c|c|}
\hline & Mean & $\mathrm{SD}$ & $\mathrm{N}$ & $\%$ \\
\hline \multicolumn{5}{|l|}{ Gender } \\
\hline Male & & & 99 & 19.8 \\
\hline Female & & & 401 & 80.2 \\
\hline Age (years) & 36.19 & 8.3 & & \\
\hline \multicolumn{5}{|l|}{ Education in NK } \\
\hline High school graduate & & & 377 & 75.4 \\
\hline Some college or higher & & & 123 & 24.6 \\
\hline \multicolumn{5}{|l|}{ Living with family members } \\
\hline Yes & & & 310 & 62 \\
\hline No & & & 190 & 38 \\
\hline \multicolumn{5}{|l|}{ Religion } \\
\hline Yes & & & 238 & 47.6 \\
\hline No & & & 262 & 52.4 \\
\hline \multicolumn{5}{|l|}{ Job } \\
\hline Yes & & & 294 & 58.8 \\
\hline No & & & 206 & 41.2 \\
\hline Discrimination experience & 14.42 & 5.17 & 206 & 41.2 \\
\hline Stress & 22.07 & 5.03 & & \\
\hline Life satisfaction & 20.79 & 6.35 & & \\
\hline
\end{tabular}

SD: standard deviation, NK: North Korea

Table 2. Estimation of maximum likelihood in the model

\begin{tabular}{lcccc}
\hline \multicolumn{1}{c}{ Paths } & Coef. & SE & $\mathrm{z}$ & $\mathrm{p}$ \\
\hline $\begin{array}{l}\text { Discrimination experience } \\
\quad \\
\quad \text { Stress }\end{array}$ & & & & \\
$\quad$ Life satisfaction & -0.405 & 0.036 & 11.31 & 0.000 \\
Stress & & & & \\
$\quad$ Life satisfaction & -0.307 & 0.044 & -6.92 & 0.000 \\
\hline
\end{tabular}

\section{RESULTS}

\section{General characteristic of subjects}

Regarding gender, the number of males was 99 (19.8\%) while the number of females was $401(80.2 \%)$. The average age was 36.19. In terms of education level, $75.4 \%$ have lower than high school education and $24.6 \%$ graduated from higher post college institutions. $62 \%$ of subjects live together with their family and $47.6 \%$ are part of a religion and $58.8 \%$ are working in South Korea (Table 1).

\section{The path of affecting stress from experience of discrimination}

\section{Goodness of fit}

To identify the path of experience of discrimination, stress and life satisfaction from North Korean refugees, we set a model and the result of analysis showed in Table 2.

The experience of discrimination significantly affects stress and stress significantly affects life satisfaction. However, the experience of discrimination did not affect life satisfaction. To be specific, the experience of discrimination significantly affect stress $(0.405, \mathrm{p}<0.001)$. With more experience of discrimination, people felt more stress. The stress affect life satisfaction $(-0.307, \mathrm{p}<0.001)$. The more stress people received, the life satisfaction became lower (Table 2, Figure 1).

\section{Verification of moderator effect}

We verified that stress has a moderator effect between experience of discrimination and life satisfaction.

There is an indirect effect for the independent variable, which in turn affects dependent variable by moderator. The analysis of indirect effect is that $\mathrm{X}$ (independent variable) $\rightarrow \mathrm{Y}$ (mediator) $\rightarrow \mathrm{Z}$ (dependent variable) should be verified. There-

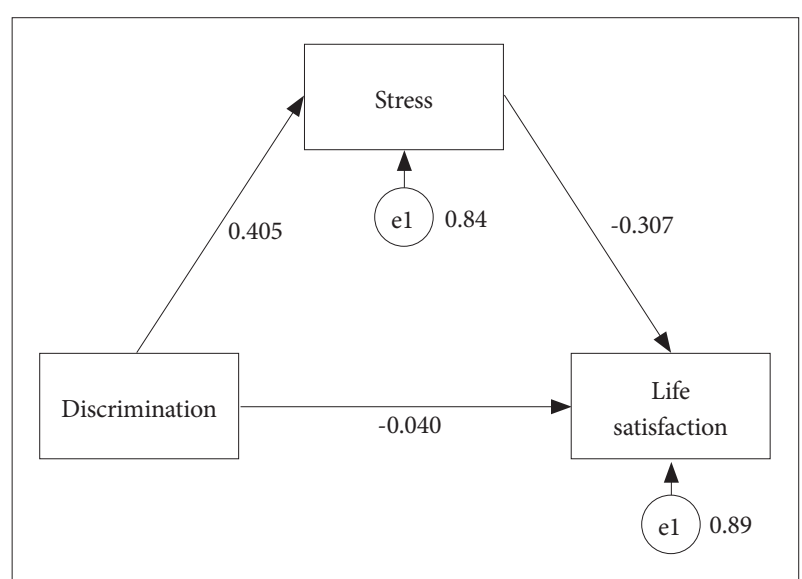

Figure 1. The path of affecting stress from experience of discrimination. Adjusted variables include: gender, age, education in North Korea, Living with family members, Religion, Job. 
Table 3. Verification of direct, indirect and total effect in the model

\begin{tabular}{lccc}
\hline \multicolumn{1}{c}{ Paths } & Direct & Indirect & Total \\
\hline Discrimination experience & & & \\
$\quad$ Stress & $0.394^{*}$ & No path & $0.394^{*}$ \\
$\quad$ Life satisfcation & -0.049 & $-0.153^{*}$ & $-0.202^{*}$ \\
Stress & & & \\
$\quad$ Life satisfaction & $-0.388^{*}$ & No path & $-0.388^{*}$ \\
${ }^{*} \alpha<0.001$ & & &
\end{tabular}

fore we statistically verified $\mathrm{X}$ affects $\mathrm{Z}$ by $\mathrm{Y}$ as a moderator.

The experience of discrimination and life satisfaction of North Korean refugees has an indirect effect. That is stress is a moderator between the experience of discrimination and life satisfaction. However, the experience of discrimination does not affect life satisfaction directly. The experience of discrimination affects stress and stress affects life satisfaction. To sum up, with more experience of discrimination, stress is higher and this stress negatively affects life satisfaction. Also the experience of discrimination does not affect life satisfaction directly but rather contributes to the total effect. Therefore, stress plays a role as a moderator (Table 3 ).

\section{DISCUSSION}

In this study, we found that stress has a moderator effect between general discrimination that North Korean refugees experience and life satisfaction. The discrimination experience among North Korean refugees has an indirect effect on life satisfaction, which is that stress is a moderator between experience of discrimination and life satisfaction. A previous study reported that perceived discrimination may produce the stress and affect health. ${ }^{21}$ In addition, the life satisfaction of the disabled was reduced by not discrimination experience but perception of one's disability. ${ }^{22}$ This finding suggests that discrimination experience can be the indirect factor on life satisfaction. Nam ee al also showed that the discrimination experience of spinal disabled person did not have a direct impact on life satisfaction and the sense of shame about disability indirectly affected life satisfaction as mediator between discrimination and life satisfaction..$^{14}$ Discrimination experience reduced life satisfaction through mediator such as stress or sense of shame rather than a direct effect on life satisfaction. The perceived stress acts as a potential route between perceived discrimination and negative life satisfaction. ${ }^{23}$

A result of Utsey et al. ${ }^{24}$ study on minorities such as African, Asian and Latino who live in the United States showed that stress from national identity and cultural racial discrimination has been verified as important predictor for quality of life. Stress is a very important variable influencing factors to increase life satisfaction for those in a vulnerable group. Our result is consistent with the findings of previous studies of vulnerable groups because North Korean refugees in South Korea are socially vulnerable and a minority group. Likewise, the discrimination experiences of North Korean refugees can predict the stress and lead to life satisfaction.

This study was meaningful in the way that we presented a new theory and model in the field of study on North Korean refugee's life satisfaction, by confirming that discrimination affect life satisfaction by stress as a mediator. Previous studies focused on non-linear study model that North Korean refugees' economic conditions, psychological characters, and the process of escape from North Korea. However, this study presents basic evidence for ways to improve the life satisfaction of North Korean refugees by identifying the effect of the parameters of stress.

North Korean refugees have failed to relieve or share their personal psychological stress due to the mono culture or closed culture in North Korean society. In addition, they have failed to recognize the concept of everyday stress and a need to relieve it. It is only natural, therefore, that North Korean refugees who enter the South experience stress while in a totally new culture and it is necessary to have them understand that practicing a variety of solutions will help them adapt to the South Korean society.

This study used data from the surveys conducted in 2009 from 500 North Korea refugees who came to South Korea in 2007 when 'Act on the Protection and Settlement Support of Residents Escaping from North Korea' was enforced. We have a limitation that this study cannot be generalized because we selected subjects who came to South Korea less than two years. Through following studies of North Korean refugees, further studies should be conducted for the association of North Korean refugee's perceived discrimination with life satisfaction.

We have, so far, taken approach to the mental health of North Korean refugees from a perspective of treatment. It features a strong inclination of consumption, which results in skeptical opinions about its effect due to financial burdens incurred from long-term treatment and intervention. Against this backdrop, a social consolidated approach will be needed along with growth through education instead of therapeutic intervention in order to promote the satisfaction with life among refugees.

\section{Acknowledgments}

This research was funded by Korea Peace Institute (grant number: KPI2009-001-A001).

This study was supported by a grant of the Korean Mental Health Technology R\&D Project, Ministry of Health \& Welfare, Republic of Korea (HM15C1054). 


\section{REFERENCES}

1. Goodkind D, West L. The North Korean famine and its demographic impact. Popul Dev Rev 2001;27:219-238.

2. Lee Y, Lee MK, Chun KH, Lee YK, Yoon SJ. Trauma experience of North Korean refugees in China. Am J Prev Med 2001;20:225-229.

3. Ministry of Unification. The Current Status of North Korean Refugees in South Korea. Seoul: Ministry of Unification; 2015.

4. Park MK, Kim BK, Kim SA, Song BH, Yang UC. North Korean Diaspora. Seoul: Institute for Peace and Unification Studies, Seoul National University; 2011.

5. Han M, Yoon J, Lee H, Kim I. An Analysis about the Current State and the Supporting System for North Korean Refugee Students. Seoul: Korean Education Development Institute; 2011.

6. Park YH. A Study about North Korean Refugee Adolescents in the Western Seoul Area. Seoul: The Rainbow Center for Adolescents; 2008.

7. Kim H. The effect of values on prejudice toward minority groups in Korea. Korean J Soc Pers Psychol 2007;21:91-104.

8. Kim HK, Lee OJ. A phenomenological study on the experience of North Korean refugees. Nurs Sci Q 2009;22:85-88.

9. Williams DR, Neighbors HW, Jackson JS. Racial/ethnic discrimination and health: findings from community studies. Am J Public Health 2003; 93:200-208.

10. Williams DR, Mohammed SA. Discrimination and racial disparities in health: evidence and needed research. J Behav Med 2009;32:20-47.

11. Choi SK, Min SJ, Cho MS, Joung H, Park SM. Anxiety and depression among North Korean young defectors in South Korea and their association with health-related quality of life. Yonsei Med J 2011;52:502-509.

12. George LK. Subjective well-being: conceptual and methodological issues in the study of psychological well-being in adulthood. Gerontologist 1979;19:210-216.

13. Bardasi E, Francesconi M. The impact of atypical employment on individual wellbeing: evidence from a panel of British workers. Soc Sci Med
2004;58:1671-1688.

14. Nam YH, Kim YS, Han SG, Kim KS. A study on influence of stigma, discrimination experience, shame, life satisfaction people with spinal cord injury-centered on the effect parameters of the shame. J Rehabil Res 2014;18:81-112.

15. Cho Y, Kim Y. Predictors of mental health risks in newly resettled North Korean refugee women. Korean J Woman Psychol 2010;15:509-527.

16. Williams DR, Yu Y, Jackson JS, Anderson NB. Racial differences in physical and mental health socio-economic status, stress and discrimination. J Health Psychol 1997;2:335-351.

17. Kim Y. A Study on North Korean Defectors' Mental Health: An Application of a Stress Process Model. Seoul: Department of social Welfare Graduate of School Seoul National University; 2006.

18. Diener E, Emmons RA, Larsen RJ, Griffin S. The satisfaction with life scale. J Pers Assess 1985;49:71-75.

19. MacCallum RC, Browne MW, Sugawara HM. Power analysis and determination of sample size for covariance structure modeling. Psychol Methods 1996;1:130-149.

20. Hu L, Bentler PM. Cutoff criteria for fit indexes in covariance structure analysis: conventional criteria versus new alternatives. Struct Equ Modeling 1999;6:1-55.

21. Pascoe EA, Smart Richman L. Perceived discrimination and health: a meta-analytic review. Psychol Bull 2009;135:531-554.

22. Corrigan P, Thompson V, Lambert D, Sangster Y, Noel JG, Campbell J. Perceptions of discrimination among persons with serious mental illness. Psychiatr Serv 2003;54:1105-1110.

23. Ying YW. Immigration satisfaction of Chinese Americans: an empirical examination. J Community Psychol 1996;24:3-16.

24. Utsey SO, Chae MH, Brown CF, Kelly D. Effect of ethnic group membership on ethnic identity, race-related stress and quality of life. Cultur Divers Ethnic Minor Psychol 2002;8:366-377. 